\title{
Layered double hydroxide/sepiolite hybrid nanoarchitectures for the controlled release of herbicides
}

\author{
Ediana Paula Rebitski, Margarita Darder and Pilar Aranda*
}

\author{
Full Research Paper \\ Address: \\ Instituto de Ciencia de Materiales de Madrid, CSIC, c/ Sor Juana Inés \\ de la Cruz 3, Cantoblanco, 28049 Madrid, Spain \\ Email: \\ Pilar Aranda - pilar.aranda@csic.es \\ ${ }^{*}$ Corresponding author \\ Keywords: \\ controlled release; hybrid nanoarchitectures; layered double \\ hydroxides; 2-methyl-4-chlorophenoxyacetic acid (MCPA); \\ nanoarchitectonics; sepiolite
}

Beilstein J. Nanotechnol. 2019, 10, 1679-1690.

doi:10.3762/bjnano.10.163

Received: 14 May 2019

Accepted: 25 July 2019

Published: 09 August 2019

This article is part of the thematic issue "Nanoarchitectonics: bottom-up creation of functional materials and systems".

Guest Editor: K. Ariga

(c) 2019 Rebitski et al.; licensee Beilstein-Institut.

License and terms: see end of document.

\begin{abstract}
In this work, organic-inorganic hybrid nanoarchitectures were prepared in a single coprecipitation step by assembling magnesium-aluminum layered double hydroxides (MgAl-LDH) and a sepiolite fibrous clay, with the simultaneous encapsulation of the herbicide 2-methyl-4-chlorophenoxyacetic acid (MCPA) as the MgAl-LDH retains its ion exchange properties. The synthetic procedure was advantageous in comparison to the incorporation of MCPA by ion exchange after the formation of the LDH/sepiolite nanoarchitecture in a previous step, as it was less time consuming and gave rise to a higher loading of MCPA. The resulting MCPA-LDH/sepiolite nanoarchitectures were characterized by various physicochemical techniques (XRD, FTIR and ${ }^{29}$ Si NMR spectroscopies, CHN analysis and SEM) that revealed interactions of LDH with the sepiolite fibers through the silanol groups present on the outer surface of sepiolite, together with the intercalation of MCPA in the LDH confirmed by the increase in the basal spacing from $0.77 \mathrm{~nm}$ for the pristine LDH to $2.32 \mathrm{~nm}$ for the prepared materials. The amount of herbicide incorporated in the hybrid nanoarchitectures prepared by the single-step coprecipitation method surpassed the CEC of LDH (ca. $330 \mathrm{mEq} / 100 \mathrm{~g}$ ), with values reaching $445 \mathrm{mEq} / 100 \mathrm{~g} \mathrm{LDH}$ for certain compositions. This suggests a synergy between the inorganic solids that allows the nanoarchitecture to exhibit better adsorption properties than the separate components. Additionally, in the release assays, the herbicide incorporated in the hybrid nanoarchitectures could be completely released, which confirms its suitability for agricultural applications. In order to achieve a more controlled release of the herbicide and to act for several days on the surface of the soil, the hybrid nanoarchitectures were encapsulated in a biopolymer matrix of alginate/zein and shaped into spheres. In in vitro tests carried out in bidistilled water, a continuous release of MCPA from the bionanocomposite beads was achieved for more than a week, while the non-encapsulated materials released the 100\% of MCPA in $48 \mathrm{~h}$. Besides, the encapsulation may allow for better handling and transport of the herbicide.
\end{abstract}




\section{Introduction}

Nanoarchitectonics is a definition attributed to the development of materials with new functionalities based on a controlled arrangement of nanoscale structural units through their mutual interactions [1]. The term "nanoarchitectonics" coined at the "MANA" research center (Nanoscale Materials Division of the National Institute of Materials Science (NIMS) in Japan) is based on five main concepts: i) controlled self-organization, ii) chemical nanomanipulation, iii) field-induced material control, iv) new manipulations of atoms and molecules, and v) theoretical modeling and design $[1,2]$. Based on these premises a large number of nanoarchitectonic materials have been prepared including mesoporous solids, self-organized block-copolymers, supramolecular materials, and macromolecular systems of DNA and cells [2-5]. In this context, clay-based nanoarchitectonic materials have been developed over the years, starting from classical pillared clays and porous clay heterostructures $(\mathrm{PCH})$ to more innovative materials involving the assembly of different types of nanoparticles and other species, and clays of different origin and morphology [6-11]. There are diverse methodologies and synthesis strategies to provide new functionalities to clays. Particularly useful for constructing nanoarchitectures is the use of organic-inorganic interphases as those provided by organoclays [12]. Besides typical 2D layered clays, fibrous (sepiolite, palygorskite) and tubular (halloysite, imogolite) clays are attracting growing interest in the development of a large variety of functional nanomaterials and nanocomposites for application in diverse fields [13-15].

Sepiolite (Figure 1A) is a natural hydrated magnesium silicate with the ideal formula $\left[\mathrm{Si}_{12} \mathrm{O}_{30} \mathrm{Mg}_{8}(\mathrm{OH}, \mathrm{F})_{4}\right]\left(\mathrm{H}_{2} \mathrm{O}\right)_{4} \cdot 8 \mathrm{H}_{2} \mathrm{O}$ $[16,17]$, which exhibits high surface area and adsorption capacity due to the presence of silanol groups on the external surface of the clay fibers. These $\equiv \mathrm{SiOH}$ groups are arranged regularly along the structural edges of the fiber, being advantageous to produce functional nanoarchitectures. Thus, in recent years the number of publications related to the assembly of different types of nanoparticulated solids (e.g., metals, metal oxides, and graphene) and sepiolite or palygorskite has increased, yielding nanoplatforms useful in a large number of applications from catalysis, environmental remediation, energy production and storage to biomedicine $[14,18]$. The co-assembly of particles can be reached through several methods, from the direct assembly of the clay to diverse nanoparticulated solids to the in situ generation of nanoparticles in the presence of the clay [14]. One of the key points in these strategies is to reach a good disaggregation of the fibrous particles to favor the exposition of the clay surface for the assembly with other particles, either present in the medium or in the process of growing. Examples are the direct assembly of carbon nanotubes and sepi-
A

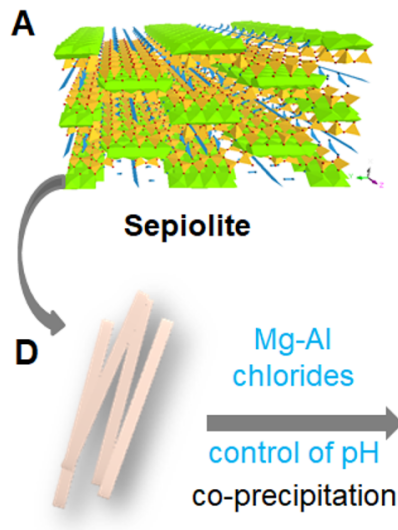

B

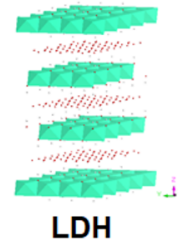

C<smiles>Cc1cc(Cl)ccc1OCC(=O)O</smiles>

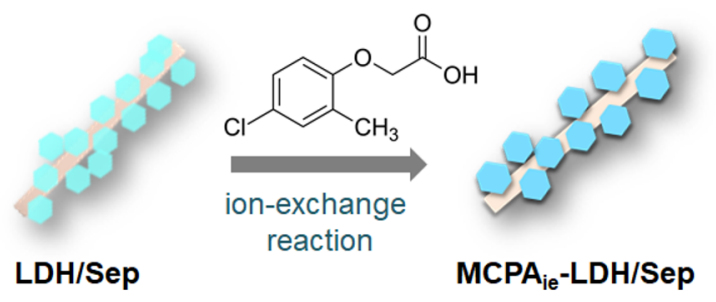

LDH/Sep

$\mathrm{MCPA}_{\mathrm{ie}}$-LDH/Sep

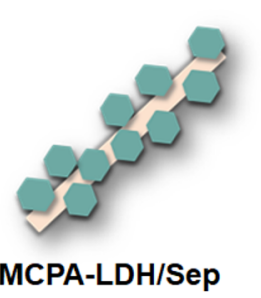

Figure 1: Schematic representations of (A) sepiolite and (B) layered double hydroxide structures, (C) molecular structure of 2-methyl-4-chlorophenoxyacetic acid (MCPA), and schemes of the synthesis of the hybrid MCPA-LDH/sepiolite nanoarchitectures by (D) ion exchange and (E) one-step coprecipitation. 
olite under ultrasonic irradiation [19] and the generation of layered titanosilicates in the presence of sepiolite [20]. In this context, the use of organic-inorganic interphases has proved highly effective to facilitate the co-assembly process, which favors the formation of more homogeneous and, in general, better organized nanoarchitectures [12].

Layered double hydroxides (LDH), often called anionic clays, are $2 \mathrm{D}$ solids of the general formula $\left[\mathrm{M}(\mathrm{II})_{1-x} \mathrm{M}(\mathrm{III})_{x}(\mathrm{OH})_{2}\right]^{x+}\left(\mathrm{A}^{n-}\right)_{x / n} \cdot m \mathrm{H}_{2} \mathrm{O}$ (Figure 1B), consisting of positively charged brucite-like layers that are balanced with anions and water molecules in the interlayer space [21]. Although there also exists in nature a Mg-Al layered double hydroxide, namely hydrotalcite, LDH materials can be easily prepared by coprecipitation from metal solutions at a controlled $\mathrm{pH}$ value. This procedure and other protocols of synthesis together with the possibility to stabilize solids involving a large variety of metal ions have provided a large variety of LDH compounds of interest in numerous applications as adsorbents of anionic pollutants, catalysts, additive of polymers, as components in diverse electrochemical devices (such as supercapacitors, sensors, and biosensors), in drug delivery and controlled-release formulations, or in non-viral gene transfection [21-26]. The fact that the stability of LDH varies with the $\mathrm{pH}$ value has proved advantageous in some of the above mentioned applications, in particular, for uses as host substrate in the immobilization of active species (e.g., drugs, pesticides, and DNA) for controlled-delivery applications [27-29]. LDH have been also used in the construction of different types of nanoarchitectonic materials. The used strategies included wet impregnation and layer-by-layer approaches to produce diverse type of multilayer heterostructures, e.g., $\mathrm{ZnCr}-\mathrm{LDH} / \mathrm{TiO}_{2}$ films [30], in situ formation of the LDH in presence of other nanoparticles, e.g., sepiolite [31], and reconstruction of the LDH from parent "layered double oxides" in the presence of diverse species, e.g., silica nanoparticles [32].

Nanoarchitectonic materials involving the growth of LDH nanoparticles in the presence of fibrous clay silicates were patented several years ago [33]. Direct co-assembly of already formed particles of each component does not produce true nanoarchitectonic materials. Hence, it is necessary to grow the LDH in the presence of the fibrous clay [31]. In fact, the presence of silanol groups along the external surface of the silicate fibers act as anchoring points at which the LDH grows, forming LDH particles with their characteristic sandrose structure surrounding the clay fibers [31]. The resulting materials may show dual ion exchange behavior due to the anion and cation exchange properties of LDH and sepiolite components, respectively. This type of nanoarchitectonic materials could be of interest as adsorbents for the removal of pollutants from water, for instance dyes [31] and, As(III) and As(V) species [34]. Moreover, they could be used as precursors for supported metal-oxide nanoparticles that could be of interest in catalysis [31]. MgAl-LDH/sepiolite nanoarchitectures have been also satisfactorily tested as nanofiller in Nafion membranes for fuelcell applications [35]. With these premises, the current aim is to ascertain if it is possible to develop organic-inorganic hybrid materials using LDH-sepiolite nanoarchitectonic materials, as the presence of an organic counterpart could be of interest for introducing additional functionalities. Thus, in this first work, we have explored the incorporation of an anionic molecule, the herbicide 2-methyl-4-chlorophenoxyacetic acid (MCPA, Figure 1C), as it is expected to easily associate with the LDH. The resulting materials showed MCPA release properties that allow for the application of these systems for the controlled delivery of this herbicide. Hybrid nanoarchitectures were prepared profiting from the anion exchange properties of the $\mathrm{MgAl}-\mathrm{LDH} /$ sepiolite and also by coprecipitation of the MgAl$\mathrm{LDH}$ in the presence of an aqueous dispersion of sepiolite in which MCPA was also present. Differences in composition, structure and release behavior between the developed hybrid nanoarchitectures prepared by the two methods were examined and analyzed. In view to apply these materials in agriculture, the efficiency of formulations based on the hybrid nanoarchitectures was explored in in vitro tests of MCPA release, confirming the improvement of retention properties. For a better control in the MCPA release, the hybrid nanoarchitectures were also combined with mixtures of alginate-zein biopolymers [36] to improve the retention properties.

\section{Results and Discussion MCPA-LDH/sepiolite hybrid nanoarchitec- tures}

The preparation of MgAl-LDH/sepiolite (LDH/Sep) hybrid nanoarchitectures was firstly achieved by ion exchange of MCPA herbicide anions with the chloride ions present in $\mathrm{LDH} / \mathrm{Sep}$ nanoarchitectures previously prepared following the protocol reported elsewhere by Gomez-Avilés et al. [31] (Figure 1D). XRD patterns (Figure 2A) of both nanoarchitectures, as prepared and after the ion exchange reaction, showed the most intense peaks in the patterns of the pure sepiolite and the LDH. The differences in the position of the most intense peak ascribed to the LDH in the neat nanoarchitectures and most of the hybrid nanoarchitectures confirm the intercalation of MCPA in the LDH supported on the sepiolite fibers. The $d(003)$ reflection is shifted towards lower $2 \theta$ angles, resulting from an increase of the basal spacing from 0.77 to $2.15 \mathrm{~nm}$, with values similar to those observed when MCPA is intercalated in the LDH [37,38]. FTIR spectra (Figure 2B) shows bands ascribed to the organic component in all of the hybrid nanoarchitectures, although, as occurs in the $\mathrm{MCPA}_{\mathrm{ie}}-\mathrm{LDH}$ 

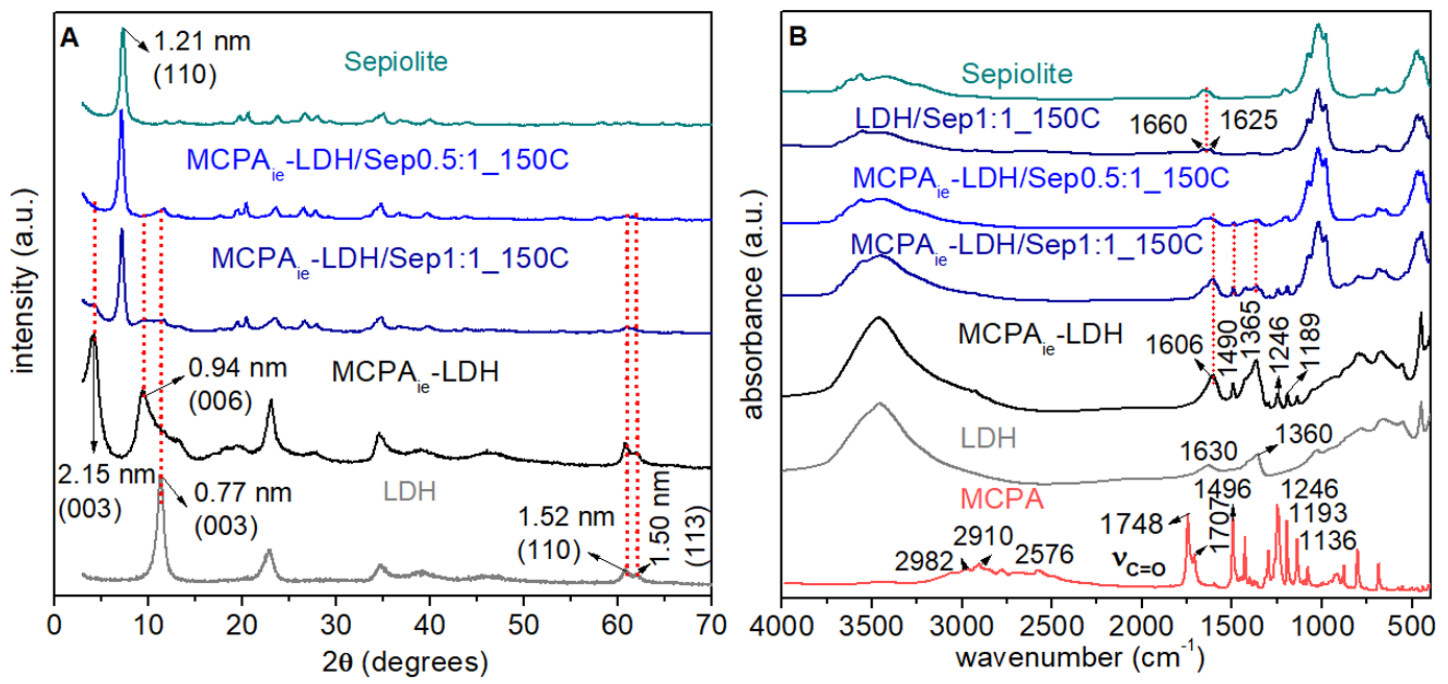

Figure 2: (A) XRD patterns and (B) FTIR spectra of individual components (sepiolite, LDH, and MCPA), MCPA ie $^{-L D H}$ intercalation compound and the neat LDH/Sep and MCPA $_{\mathrm{ie}}-\mathrm{LDH} / \mathrm{Sep}$ hybrid nanoarchitectures.

intercalation compound, interactions with the inorganic substrate modified the position of the bands. This affects specially to the very intense bands at 1748 and $1707 \mathrm{~cm}^{-1}$ assigned to the $v_{\mathrm{C}=\mathrm{O}}$ vibration modes of the carboxylic group of MCPA, which are not observed in the spectra of both the $\mathrm{MCPA}_{\mathrm{ie}}-\mathrm{LDH}$ and the $\mathrm{MCPA}_{\mathrm{ie}}-\mathrm{LDH} / \mathrm{Sep} 1: 1 \_150 \mathrm{C}$ hybrids (Figure 2B). They are shifted towards lower wavenumbers expected at around $1610 \mathrm{~cm}^{-1}$ (symmetric and asymmetric stretching vibration of ionized $\mathrm{COO}^{-}$groups) [39] as the carboxylic group should be present as carboxylate. In fact, the spectra show a large band in the range of $1630-1600 \mathrm{~cm}^{-1}$ due to the overlap of such bands with the one ascribed to $\delta_{\mathrm{HOH}}$ vibration modes of water molecules adsorbed on the inorganic solids that appear at around $1630 \mathrm{~cm}^{-1}$ [40]. In addition around 1360 and $1365 \mathrm{~cm}^{-1}$, in the initial $\mathrm{LDH}$ and in the $\mathrm{MCPA}_{\mathrm{ie}}-\mathrm{LDH}$, a possible contamination with carbonate ions during the preparation of the materials is observed (Figure 2B) [41].

The amounts of MCPA present in each nanoarchitecture were determined by elemental chemical analysis ( $\mathrm{CHN}$ ) and expressed in relation to the amount of LDH present in the nanoarchitectures (Table 1). The expected anion exchange capacity (AEC) of the LDH is around $330 \mathrm{mEq} / 100 \mathrm{~g} \mathrm{LDH}$, and so the content in MCPA in the $\mathrm{MCPA}_{\mathrm{ie}}-\mathrm{LDH}$ intercalation compound suggests the ion exchange process is incomplete in the adopted experimental conditions. The content of MCPA in the $\mathrm{MCPA}_{\mathrm{ie}}-\mathrm{LDH} / \mathrm{Sep} 1: 1 \_150 \mathrm{C}$ hybrid nanoarchitecture is similar to that of the $\mathrm{MCPA}_{\mathrm{ie}}-\mathrm{LDH}$ hybrid. However, the expected content for a complete ion exchange is reached in the $\mathrm{MCPA}_{\mathrm{ie}^{-}}$ LDH/Sep0.5:1_150C material. This effect could be ascribed to a lower degree of agglomeration of the $\mathrm{LDH}$ particles grown on the sepiolite fibers in the nanoarchitecture with lower content in $\mathrm{LDH}$, which may favor a faster ion exchange reaction. In fact, in $\mathrm{MCPA}_{\mathrm{ie}}-\mathrm{LDH} / \mathrm{Sep} 0.3: 1 \_150 \mathrm{C}$, in which the sepiolite fibers are less covered, the amount of MCPA surpassed the ion exchange capacity of the LDH. This fact might be related to interaction of MCPA anions with hydrogen atoms of the silanol groups on the surface of sepiolite, acting as new points for MCPA adsorption. In fact, sepiolite may adsorb MCPA up to approx. $100 \mathrm{mg}$ of MCPA per gram of sepiolite (see Figure S1, Supporting Information File 1).

Figure 3 shows images obtained by FE-SEM and TEM from the neat sepiolite and from the hybrid nanoarchitectures. The

Table 1: Amounts of MCPA in $\mathrm{mEq} / 100 \mathrm{~g}$ of the hybrid and materials prepared by the ion exchange method.

\begin{tabular}{llll} 
sample & LDH/Sep real ratio & MCPA-LDH/Sep real ratio & mEq of MCPA/100 g of LDH \\
\hline MCPA $_{\text {ie-LDH }}$ & - & - & 278 \\
MCPA $_{\text {ie-LDH/Sep1:1_150C }}$ & $0.94: 1$ & $0.90: 1$ & 269 \\
MCPA $_{\text {ie-LDH/Sep0.5:1_150C }}$ & $0.47: 1$ & $0.45: 1$ & 325 \\
MCPA $_{\text {ie-LDH/Sep0.3:1_150C }}$ & $0.28: 1$ & $0.27: 1$ & 452
\end{tabular}



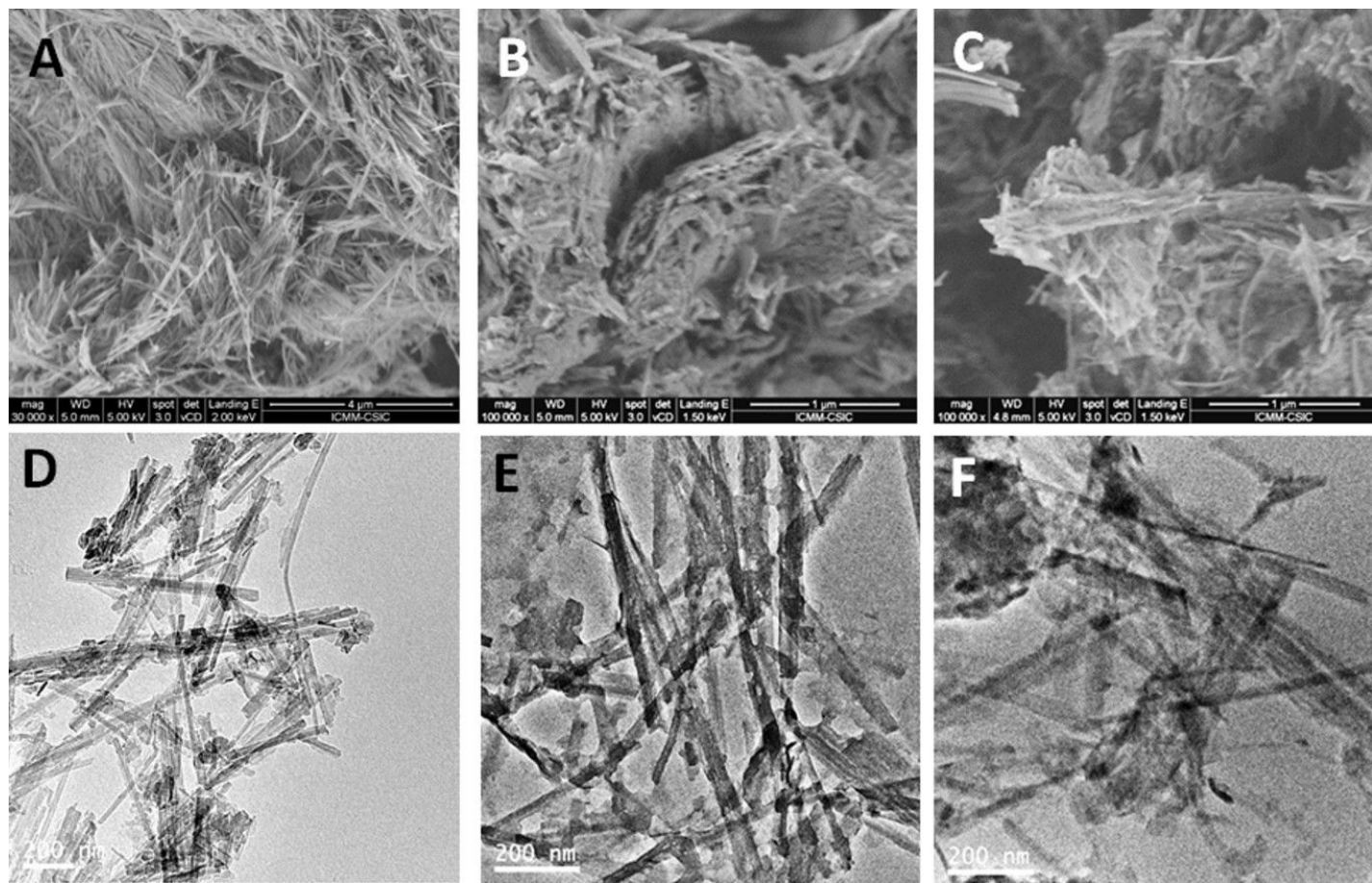

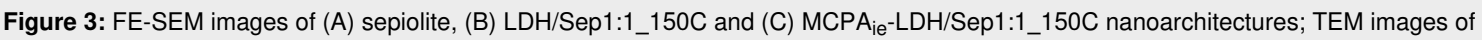
(D) LDH/Sep0.5:1_150C, and the LDH/Sep1:1_150C nanoarchitecture (E) before and (F) after the ion exchange treatment with MCPA.

FE-SEM images show that the sepiolite fibers appear covered and compacted after the coprecipitation process to produce the corresponding nanoarchitecture. The aspect of the as prepared material and the material recovered after the intercalation of MCPA in the LDH component does not vary significantly. This fact is confirmed by TEM (Figure 3E,F), where it is possible to distinguish the presence of small flat particles attached to the fibers in both nanoarchitectures. These images also confirm that the ion exchange treatment is in fact a topotactic intercalation process that does not affect the nature of the $\mathrm{LDH} /$ sepiolite nanoarchitecture, confirming also the stability of this type of materials. In addition, FE-SEM and TEM images (Figure S2, Supporting Information File 1) show that the starting LDH and the $\mathrm{MCPA}_{\mathrm{ie}}-\mathrm{LDH}$ material exhibit small and uniform particles around $100 \mathrm{~nm}$ in diameter.

\section{MCPA-LDH/sepiolite hybrid nanoarchitectures prepared via coprecipitation}

MCPA-LDH intercalation compounds can be also produced by coprecipitation of the LDH in the presence of sepiolite and MCPA. The high $\mathrm{pH}$ value during the formation of MgAl-LDH facilitates the incorporation of MCPA as charge-compensating interlayer anion. The amount of adsorbed MCPA varies with the $\mathrm{LDH} /$ sepiolite ratio in the hybrid nanoarchitecture. Unexpectedly, large amounts of MCPA are taken up when the amount of LDH is reduced (Table 2). Moreover, it seems that the presence of large amounts of MCPA is accompanied by a lower yield of assembled LDH particles in the nanoarchitecture, which can be reduced to half for nanoarchitectures with a theoretical $\mathrm{LDH} /$ sepiolite composition of $0.5: 1$. In most of the prepared hybrid nanoarchitectures, the amount of MCPA exceeds the anionic exchange capacity of the LDH (ca. $330 \mathrm{mEq} / 100 \mathrm{~g}$ ), which suggests that a part of the MCPA is adsorbed by another mechanism, perhaps on the external surface of the sepiolite clay or in interaction with the clay and the LDH particles. We have confirmed that at the $\mathrm{pH}$ value used in the synthesis process there is no precipitation of Al-MCPA or Mg-MCPA salts, although at lower $\mathrm{pH}$ values it is possible to produce precipitates in the presence of $\mathrm{Al}^{3+}$ ions. As reported in previous studies [42] and mentioned above, it has been demonstrated that sepiolite does not absorb large amounts of MCPA. However, we have observed that the adsorption of MCPA on sepiolite increases in the presence of $\mathrm{Mg}^{2+}$ and $\mathrm{Al}^{3+}$ salts at $\mathrm{pH}$ values below those required for the precipitation of the LDH (Table S1, Supporting Information File 1). This might occur during the coprecipitation of the LDH in the presence of MCPA. Given that this synthesis involves an organic molecule, the hybrid nanoarchitectures were heat-treated at $150{ }^{\circ} \mathrm{C}$ as in [31], and also at a lower temperature of $60{ }^{\circ} \mathrm{C}$. Both thermal treatments resulted in similar materials, showing that lower temperatures could be used when less stable organic molecules are involved. 
Table 2: LDH yield, LDH/Sep ratio and amount of MCPA incorporated in the hybrid nanoarchitectures prepared via coprecipitation.

\begin{tabular}{llll} 
sample & LDH yield (\%) & LDH/Sep real ratio & mEq MCPA/100 g LDH \\
\hline MCPA-LDH & 89.7 & - & 303 \\
MCPA-DH/Sep2:1_60C & 84.0 & $1.68: 1$ & 336 \\
MCPA-LDH/Sep2:1_150C & 82.0 & $1.64: 1$ & 356 \\
MCPA-LDH/Sep1:1_60C & 81.0 & $0.81: 1$ & 385 \\
MCPA-LDH/Sep1:1_150C & 78.0 & $0.78: 1$ & 421 \\
MCPA-LDH/Sep0.5:1_60C & 78.0 & $0.39: 1$ & 433 \\
MCPA-LDH/Sep0.5:1_150C & 77.0 & $0.38: 1$ & 445 \\
MCPA-LDH/Sep0.3:1_60C & 54.4 & $0.18: 1$ & 1266 \\
MCPA-LDH/Sep0.3:1_150C & 41.4 & $0.19: 1$ & 1180
\end{tabular}

XRD patterns of the hybrid nanoarchitectures (Figure 4) confirmed that in all cases MCPA is intercalated in the interlayer space of the coprecipitated LDH, as indicated by the presence of the $d(003)$ reflection peak characteristic of the LDH structure at a $2 \theta$ angle around $4.5^{\circ}$. From that reflection, basal spacing values of $2.32 \mathrm{~nm}$ are deduced in the LDH present in the hybrid nanoarchitectures, which is similar to that determined in MCPA-LDH intercalation compounds prepared by both ion exchange and coprecipitation. The structure of sepiolite is maintained in all samples, independent of the proportion of $\mathrm{LDH}$, while the most intense peak of the LDH decreased in intensity at the same time that the proportion of $\mathrm{LDH} /$ sepiolite is lowered. In addition, the LDH peaks $d(110)$ and $d(113)$ are observed in all the nanoarchitectures formed, confirming the formation of the LDH structure for all the studied LDH/sepiolite ratios.

The formation of true hybrid nanoarchitectures was confirmed by infrared and NMR spectroscopy. For this purpose, the spec-

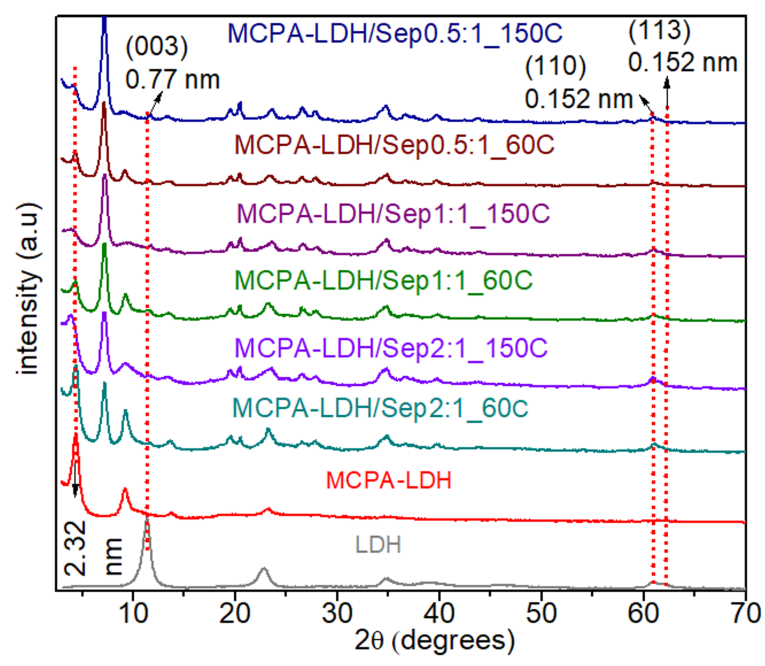

Figure 4: XRD patterns of hybrid nanoarchitectures prepared by coprecipitation of MgAl-LDH in the presence of sepiolite and MCPA at different theoretical LDH/sepiolite ratios $(x: 1)$. tral region of the $\mathrm{OH}$ vibration bands of the $\mathrm{Si}-\mathrm{OH}$ and $\mathrm{Mg}-\mathrm{OH}$ groups was analyzed in detail. These bands appear at approximately 3720 and $3680 \mathrm{~cm}^{-1}$, respectively, in the IR spectrum of pure sepiolite [43]. The band attributed to the $\mathrm{OH}$ vibration of the $\mathrm{Mg}-\mathrm{OH}$ groups is observed in the hybrid nanoarchitectures with apparently the same intensity. In contrast, the intensity of the band at $3720 \mathrm{~cm}^{-1}$ associated with vibrations of $\mathrm{Si}-\mathrm{OH}$ groups is attenuated in the hybrid nanoarchitectures, indicating that part of those silanol groups are in interaction with other species as observed in other modifications of sepiolite [44-47]. This perturbation originates from hydrogen interactions between the silanol groups of the silicate and LDH particles, inducing a shift of the associated IR band towards lower frequencies. In fact, the band practically becomes imperceptible, mainly in the MCPA-LDH/Sep hybrid nanoarchitectures after thermal treatment at the highest temperature (Figure 5A). Also, this band is not observed in samples containing the highest proportions of $\mathrm{LDH}$ with respect to sepiolite, where the LDH particles may be completely covering the sepiolite fibers. The chemical interactions between the LDH and sepiolite components in the LDH/Sep hybrid nanoarchitectures prepared by coprecipitation were also corroborated by ${ }^{29}$ Si MAS NMR (Figure 5B). As previously reported [31], the spectrum of MgAl-LDH/Sep is different from that of pure sepiolite. The spectrum of neat sepiolite shows three $\mathrm{Q}^{3}$ signals and one $\mathrm{Q}^{2}$ signal. The latter one is associated with the silanol groups [48]. In the spectra of the MCPA-LDH/Sep0.5:1_60C and MCPA-LDH/Sep0.5:1_150C hybrid nanoarchitectures the $\mathrm{Q}^{3}$ signals are slightly shifted to values around $-92.3,-94.8$ and -98.4 ppm, while the $\mathrm{Q}^{2}$ signal is practically not detected (Figure 5B). In addition, a new $\mathrm{Q}^{3}$ signal, is observed at $-96.6 \mathrm{ppm}$, which could be associated with a new type of $\mathrm{Si}$ environment coming from the condensation of the silanol $-\mathrm{OH}$ groups on the surface of the sepiolite fibers with the hydroxy groups of the co-precipitated LDH particles, as previously reported for neat LDH/sepiolite nanoarchitectures [31]. The small differences observed in the FTIR and NMR spectra of hybrid nanoarchitectures prepared by consolidation at 60 and $150{ }^{\circ} \mathrm{C}$ 

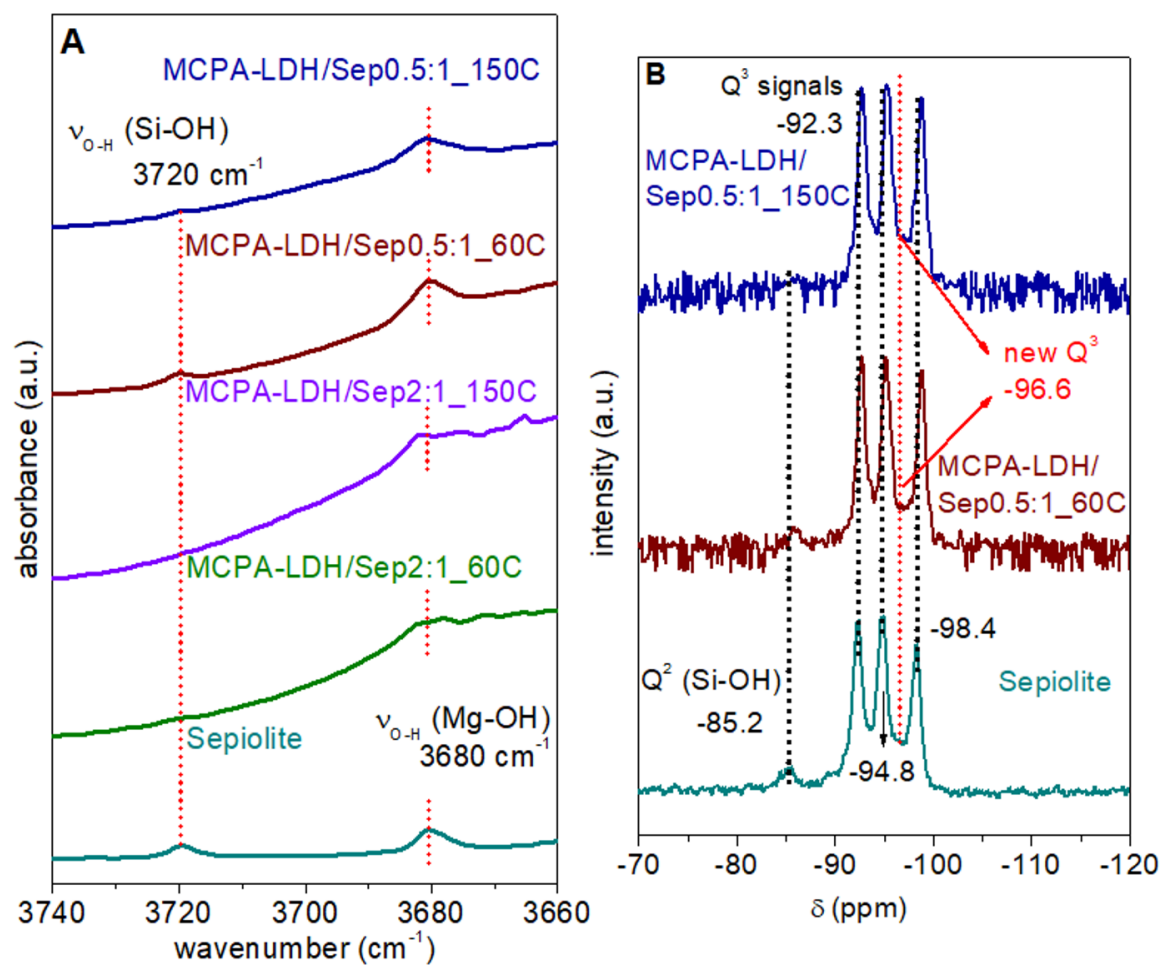

Figure 5: (A) FTIR (3800 to $3600 \mathrm{~cm}^{-1}$ region) and (B) ${ }^{29}$ Si MAS NMR spectra of neat sepiolite and hybrid nanoarchitectures prepared by coprecipitation of the MgAl-LDH in the presence of sepiolite and MCPA at different theoretical LDH/sepiolite ratios $(x: 1)$.

indicate the high stability of the prepared materials after both thermal treatments. This confirms the possibility of consolidating the hybrid nanoarchitectures at mild temperatures below $150{ }^{\circ} \mathrm{C}$. FTIR spectroscopy also confirms the incorporation of MCPA through interaction with the LDH (Figure S3, Supporting Information File 1), as discussed for the hybrid nanoarchitectures prepared by ion exchange.

The FE-SEM images of the MCPA-LDH/Sep hybrid nanoarchitectures (Figure 6) confirm that sepiolite fibers are covered by LDH nanoparticles, which are more agglomerated in the hybrid nanoarchitectures containing higher amounts of LDH. In the structures with lower LDH content, the layered solid grows in particles of smaller size and TEM images clearly confirm that they remain attached to the silicate fibers (Figure 6F).

\section{In vitro release of MCPA in water}

The release of MCPA from the hybrid nanoarchitectures was evaluated in in vitro tests in deionized water ( $\mathrm{pH}$ approx. 5.5), simulating the conditions of rain. The kinetics of the release depends on the nanoarchitecture composition (Figure 7), but in all cases an initial fast release is observed, followed by another zone showing slower kinetics. These two regimes could be due to the initial release of more accessible MCPA, most likely related to interparticle diffusion, while the second zone could be due to diffusion of the intercalated herbicide molecules. The MCPA-LDH system showed the slowest release of MCPA, with around 35\% lixiviated from the inorganic host after $8 \mathrm{~h}$, being this value similar to those found for the release from $\mathrm{MCPA}_{\mathrm{ie}^{-}}$ LDH [49]. Other studies reported a complete release of the herbicide in a similar time [50]. In contrast, the release from the MCPA $_{i e}-\mathrm{LDH} / \mathrm{Sep} 1: 1 \_150 \mathrm{C}$ hybrid nanoarchitecture, where the MCPA was incorporated by ion exchange showed a very rapid release, with practically $75 \%$ of the MCPA leached after the first $8 \mathrm{~h}$. This result clearly confirms that the presence of the LDH as small nanoparticles attached to the fibrous clay may favor a rapid release of the intercalated species. In the hybrid nanoarchitectures prepared by coprecipitation and the same $\mathrm{LDH} /$ sepiolite ratio the release is slower. The slowest release occurred from the nanoarchitecture consolidated at $60{ }^{\circ} \mathrm{C}$. A similar trend was observed when comparing the release from coprecipitated hybrid nanoarchitectures of other compositions consolidated at 60 and $150{ }^{\circ} \mathrm{C}$ (Figure S4, Supporting Information File 1). There is no clear explanation yet for this behavior. It might be ascribed to the different degree of hydration or the presence of $\mathrm{OH}^{-}$species in the systems consolidated at lower temperature, which determines a different mechanism of attack of $\mathrm{H}^{+}$to produce the degradation of the LDH and the subsequent release of entrapped MCPA. The fastest kinetics is observed with the lowest LDH content (Figure 7 and Figure S4, 

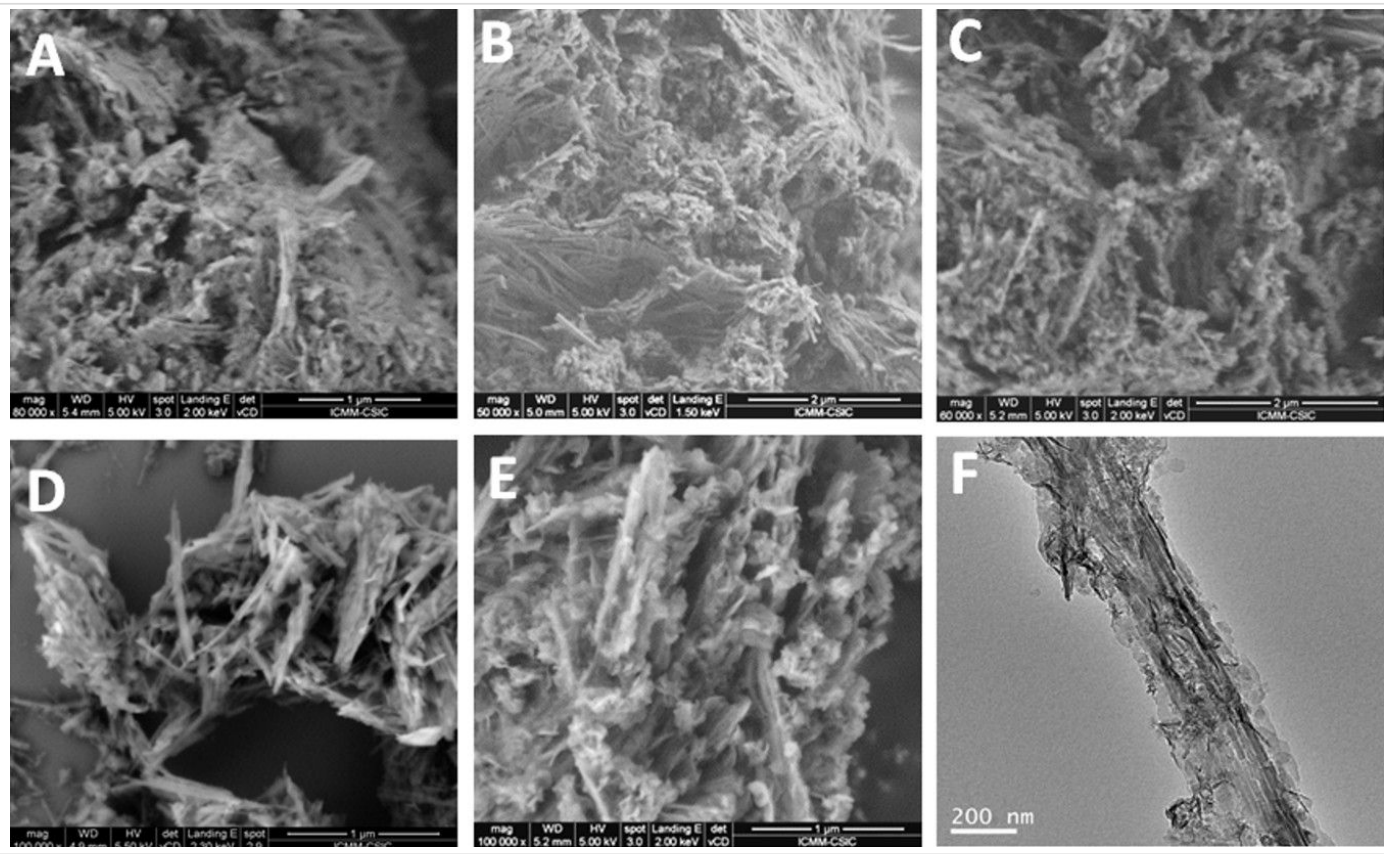

Figure 6: FE-SEM images of (A) MCPA-LDH/Sep2:1 150C, (B) MCPA-LDH/Sep1:1_150C, (C) MCPA-LDH/Sep0.5:1 60C, (D) LDH/Sep0.5:1_150C and (E) MCPA-LDH/Sep0.5:1_150C hybrid nanoarchitectures prepared by coprecipitation from different LDH/sepiolite ratios; (F) TEM image of the MCPA-LDH/Sep0.5:1_60C hybrid nanoarchitecture.
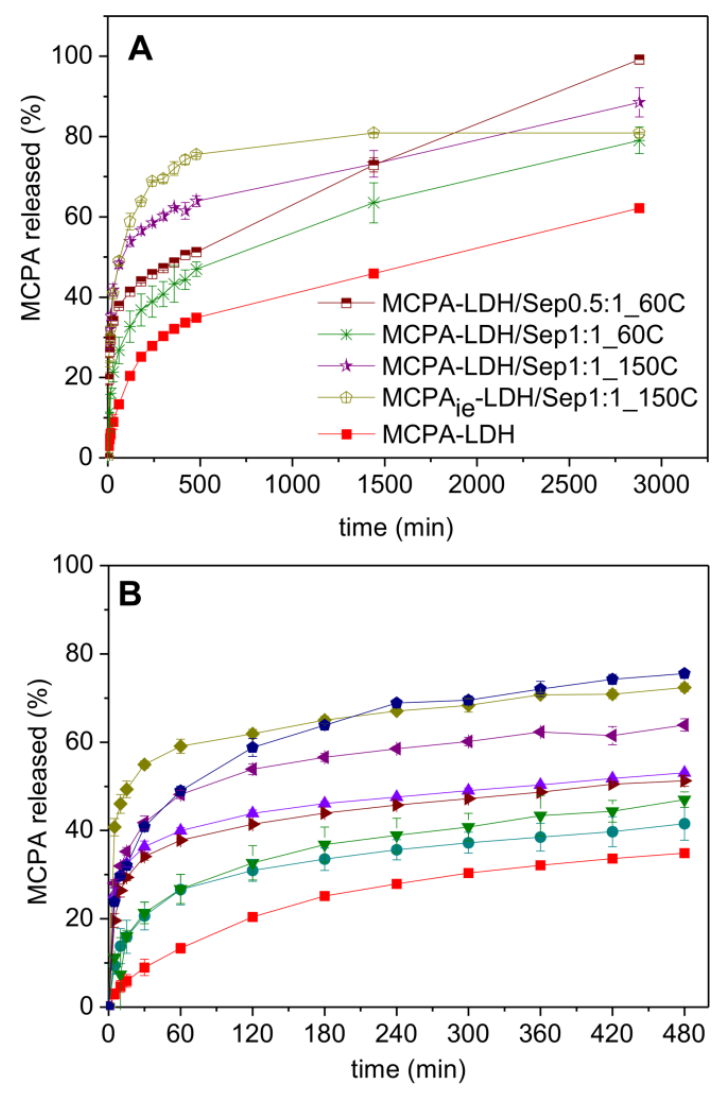

Figure 7: (A) In vitro release of MCPA from the hybrid formulations in deionized water ( $\mathrm{pH}$ approx. 5.5), and (B) zoom of the same graph showing the release behavior in the first 500 min of the study.
Supporting Information File 1). This behavior is probably related to the fact that size and aggregation state of the LDH nanoparticles increase with the LDH content in the nanoarchitecture, slowing down the kinetics of the process. The measured release after $8 \mathrm{~h}$ of contact with water varies with values of around $50 \%$ for nanoarchitectures consolidated at $60{ }^{\circ} \mathrm{C}$ (e.g., 43 and $51 \%$ for the $1: 1$ and $0.5: 1 \mathrm{LDH} / \mathrm{Sep}$ nanoarchitectures, respectively) to around $70 \%$ for nanoarchitectures consolidated at $150{ }^{\circ} \mathrm{C}$ (e.g., $73 \%$ for MCPA-LDH/Sep1.1_150C, Figure 7B). After $8 \mathrm{~h}$ the release evolves differently towards a steady state, and after $48 \mathrm{~h}$ only the MCPA-LDH/Sep0.5:1_60C system completely released MCPA. These results confirm that the release of the herbicide from the hybrid nanoarchitectures may be tuned by selecting the specific composition and characteristics of the system, which makes them of interest for agricultural purposes.

Given that the amount of initial release of MCPA in all the formulations is quite high, the encapsulation of the hybrid nanoarchitectures in a protective biopolymer matrix was proposed to afford a better control over the release of the herbicide. In a previous study [49], a biopolymer mixture of alginate and zein incorporating the $\mathrm{MCPA}_{\mathrm{ie}}-\mathrm{LDH}$ hybrid prepared by ion exchange was able to reduce the initial release of MCPA by approximately $10-15 \%$ in the first $8 \mathrm{~h}$. In the current work, the MCPA-LDH/Sep0.5:1_60C nanoarchitecture was selected, as it releases $100 \%$ of the herbicide after a period of $48 \mathrm{~h}$. The hybrid was dispersed in an alginate/zein matrix, with $17 \%$ of 
zein with respect to the total biopolymer mass. The mixture was added dropwise to a $\mathrm{CaCl}_{2}$ solution to produce bionanocomposite beads $[36,49]$. The encapsulation efficiency of the prepared bionanocomposite material was $51.2 \%$, similar to that of other release systems based on the same encapsulation matrix [36].

In the bionanocomposite beads, the hydrophilicity of alginate is reduced by the presence of zein, contributing to a better control over the herbicide release. Figure 8 shows that release of MCPA from the A-Z@MCPA-LDH/Sep system is slower in the first $8 \mathrm{~h}$ than release from non-encapsulated systems, reaching approx. $40 \%$ after $48 \mathrm{~h}$. A continuous study of the A-Z@MCPA-LDH/Sep0.5:1_60C formulation over 8 days was carried out, showing a release close to $70 \%$ in the presence of the biopolymer matrix. This result suggests that the bionanocomposite could reach $100 \%$ of MCPA release after about two weeks.
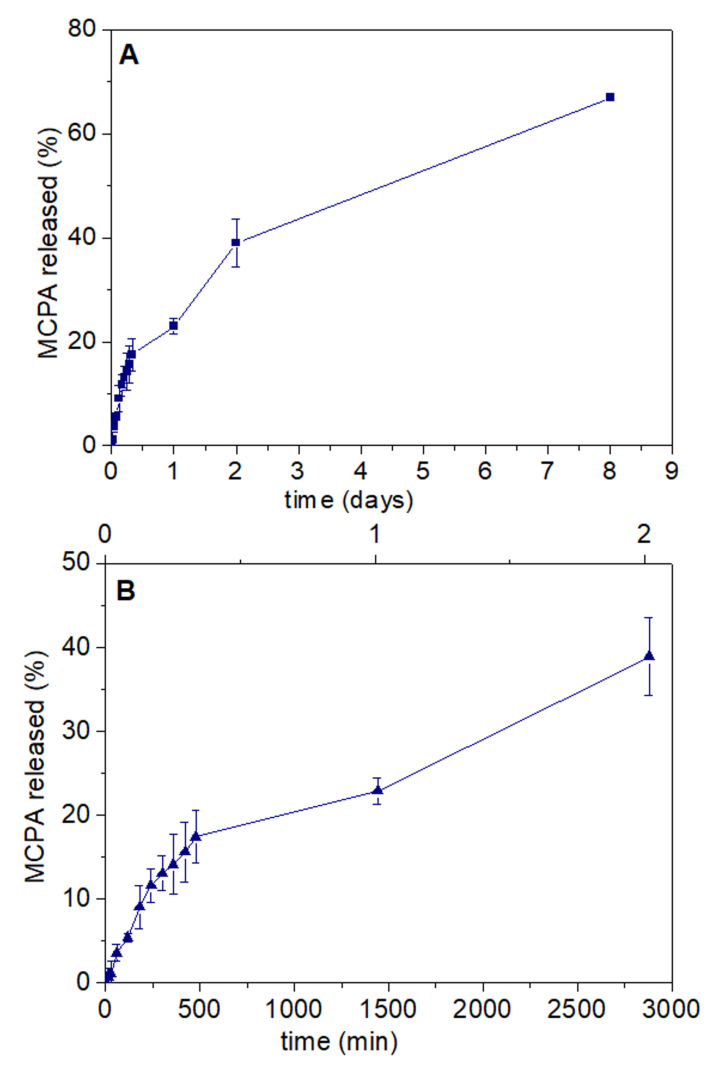

Figure 8: (A) In vitro release of MCPA encapsulated in the A-Z@MCPA-LDH/Sep bionanocomposite system over a period of 8 days in deionized water ( $\mathrm{pH} 5.5)$, and (B) zoom of the same graph in the first $48 \mathrm{~h}$ of release.

\section{Conclusion}

This work reports on two procedures to prepare hybrid LDH/ sepiolite nanoarchitectonic materials in which the herbicide MCPA is intercalated in the inorganic layered compound. The stability of the prepared MgAl-LDH/sepiolite nanoarchitectures allows for the ion exchange of interlayer anions by the anionic MCPA species. Moreover, it is possible to produce hybrid MCPA-LDH/sepiolite nanoarchitectures in a single coprecipitation step. This last approach allows for the incorporation of higher amounts of MCPA than the ion exchange reaction with the additional advantage of being less time-consuming. FTIR and ${ }^{29} \mathrm{Si}$ NMR spectroscopic analysis corroborated that the LDH particles in the coprecipitated hybrid nanoarchitecture are chemically linked to the silanol groups that cover the silicate fibers, producing stable systems even using consolidation temperatures as low as $60{ }^{\circ} \mathrm{C}$. The developed hybrid nanoarchitectures have been tested in vitro as systems for the controlled release of the incorporated organic species MCPA. In vitro tests carried out in deionized water showed that the herbicide release kinetics depended on the nanoarchitecture composition and the method of preparation. The materials with higher LHD content showed slower release rates. The herbicide could be completely released from the hybrid nanoarchitectures, confirming their suitability for the controlled release of pesticides in agriculture. To better control the release process, the hybrid nanoarchitectures can be encapsulated in a protective biopolymer matrix, such as alginate-zein, which delays the complete release up to several weeks. The presence of sepiolite in the hybrid nanoarchitectures could associate other active species to the formulation, profiting from the high capacity of this clay to adsorb numerous types of molecules. Finally, it is worthy to mention that the coprecipitation method opens the way to the production of other hybrid systems incorporating diverse organic and polymeric anionic species associated with nanometric LDH particles for controlled drug delivery and other applications.

\section{Experimental}

\section{Starting reagents and materials}

4-Chloro-2-methylphenoxyacetic acid (MCPA) was purchased from Sigma-Aldrich ( $M_{\mathrm{W}} 200.62 \mathrm{~g} \cdot \mathrm{mol}^{-1}, 97 \%$ purity). Sepiolite from Vallecas-Vicálvaro (Spain) was provided by TOLSA S.A. as Pangel ${ }^{\circledR}$ S9, a commercial product of rheological grade that contains more than $95 \%$ pure sepiolite. Zein $(Z)$ from maize, and alginate (A) were purchased from Sigma-Aldrich. Absolute ethanol was supplied by Panreac. Aqueous solutions were prepared from chemicals of analytical reagent grade: $\mathrm{AlCl}_{3} \cdot 6 \mathrm{H}_{2} \mathrm{O}$ (>99\%, Fluka), $\mathrm{MgCl}_{2} \cdot 6 \mathrm{H}_{2} \mathrm{O}$ (99\%, Carlo Erba), $\mathrm{NaOH}\left(\geq 98 \%\right.$, Fluka), $\mathrm{ZnCl}_{2}(>98 \%$, Fluka). Deionized water (resistivity $=18.2 \mathrm{M} \Omega \cdot \mathrm{cm}$ ) was obtained with a Maxima Ultrapure Water from Elga.

\section{Preparation of MCPA-LDH/sepiolite nanoarchitectures}

$\mathrm{MgAl}-\mathrm{LDH} /$ sepiolite (LDH/Sep) nanoarchitectures were prepared following the protocol described elsewhere [31]. In brief, 
a solution of $\mathrm{MgCl}_{2}$ and $\mathrm{AlCl}_{3}$ (9.34 $\mathrm{mmol}$ and $4.68 \mathrm{mmol}$ ) was drop-wise added to a dispersion of $4 \mathrm{~g}$ of sepiolite in $350 \mathrm{~mL}$ of deionized water at a rate of $2 \mathrm{~mL} / \mathrm{min}$, while kept under $\mathrm{N}_{2}$ flux to assure the removal of $\mathrm{CO}_{2}$. At the same time, a solution of $1 \mathrm{M} \mathrm{NaOH}$ was added with the 800 Dosino automatic dispenser from Metrohm in order to maintain the $\mathrm{pH}$ value constant at 9 . After the addition of the salts to reach $\mathrm{LDH} /$ sepiolite products with $1: 1,0.5: 1$ or $0.3: 1$ theoretical weight ratio, the system was kept under magnetic stirring under a $\mathrm{N}_{2}$ flux for $24 \mathrm{~h}$. The resulting $\mathrm{LDH} / \mathrm{Sep}$ products were recovered by centrifugation, washed three times with deionized water, and dried at $150{ }^{\circ} \mathrm{C}$ under $\mathrm{N}_{2}$ flux ( $100 \mathrm{~mL} / \mathrm{min}$ ) for $3 \mathrm{~h}$ to consolidate the nanoarchitectures. For comparison, a LDH solid was prepared in the same way but without the presence of sepiolite. The intercalation of MCPA by ion exchange was performed using a solution of the herbicide prepared by dissolving $1.5 \mathrm{~g}$ of MCPA in $125 \mathrm{~mL}$ of ionized water and adjusting its $\mathrm{pH}$ value to 7 with $1 \mathrm{M} \mathrm{NaOH}$ to assure the presence of the organic molecule as an anion. This solution was slowly added to a dispersion prepared with $0.5 \mathrm{~g}$ of the selected LDH/Sep nanoarchitecture, or the $\mathrm{LDH}$, in $125 \mathrm{~mL}$ of deionized water, with a final $\mathrm{pH}$ of approximately 9 . The system was then kept under magnetic stirring and $\mathrm{N}_{2}$ flux for $72 \mathrm{~h}$ at room temperature. Subsequently, the solid was recovered by centrifugation, washed three times with water and dried at $60{ }^{\circ} \mathrm{C}$ overnight. The resulting materials were labeled as $\mathrm{MCPA}_{\mathrm{ie}}-\mathrm{LDH}, \mathrm{MCPA}_{\mathrm{ie}}-\mathrm{LDH} / \mathrm{Sep} 1: 1_{-} 150 \mathrm{C}$, $\mathrm{MCPA}_{\mathrm{ie}}-\mathrm{LDH} / \mathrm{Sep} 0.5: 1_{-} 150 \mathrm{C}$ and MCPAie ${ }^{-}$ LDH/Sep $0.3: 1 \_150 \mathrm{C}$.

In the same way, MCPA-LDH/sepiolite hybrid nanoarchitectures were prepared in one step by coprecipitation of the MgAlLDH in presence of both sepiolite and MCPA. LDH formed on the surface of sepiolite fibers with intercalated herbicide anions instead of $\mathrm{Cl}^{-}$ions. To this end, $4 \mathrm{~g}$ of sepiolite and $2.5 \mathrm{~g}$ of MCPA were dissolved in $350 \mathrm{~mL}$ of decarbonated deionized water. Again, the solution of $\mathrm{MgCl}_{2}$ and $\mathrm{AlCl}_{3}$ was varied in order to obtain hybrid nanoarchitectures with 2:1, 1:1, 0.5:1 and 0.3:1 theoretical LDH/Sep weight ratio. After the addition of the salts, the system was kept under magnetic stirring and $\mathrm{N}_{2}$ flux for $24 \mathrm{~h}$. The solid was washed and recovered by centrifugation and then subjected to a controlled heat treatment at 60 or $150{ }^{\circ} \mathrm{C}$ for $3 \mathrm{~h}$ under air flow $(100 \mathrm{~mL} / \mathrm{min})$ to consolidate the nanoarchitectures prepared from MCPA-LDH/Sep. The hybrid nanoarchitectures were labeled as MCPA-LDH/Sep2:1_60, MCPA-LDH/Sep2:1_150C, MCPA-LDH/Sep1:1_60C, MCPALDH/Sep1:1_150C, MCPA-LDH/Sep0.5:1_60C and MCPALDH/Sep0.5:1_150C, MCPA-LDH/Sep0.3:1_60C and MCPALDH/Sep0.3:1_150C. Following a similar protocol, the LDH was also coprecipitated in the presence of only MCPA to produce the corresponding MCPA-LDH intercalated material, which in this case was dried at $60{ }^{\circ} \mathrm{C}$.

\section{Preparation of alginate-zein bionanocomposite beads}

Alginate/zein beads were prepared following the following procedure adapted from Alcântara and co-workers [36]: i) The required amount of alginate to achieve a final total concentration of $2 \%$ in biopolymers was dissolved in $83 \mathrm{~mL}$ of water previously heated at $60{ }^{\circ} \mathrm{C}$; ii) the required amount of zein $(17 \%$ of the total biopolymer mass) and $34 \mathrm{mg}$ of MCPA or the required amount of the MCPA-LDH or MCPA-LDH/Sep hybrids containing $34 \mathrm{mg}$ of MCPA were incorporated into $20 \mathrm{~mL}$ of ethanol-water $(80 \%, \mathrm{v} / \mathrm{v})$; iii) the mixture was homogenized, and then slowly added to an alginate solution under magnetic stirring for approximately $30 \mathrm{~min}$; iv) the formed gel was poured with a burette into a $5 \% \mathrm{CaCl}_{2}$ solution to form the bionanocomposite beads, which were kept under constant stirring for $15 \mathrm{~min}$. At the end of the process, the beads were washed with deionized water to remove residual $\mathrm{Ca}^{2+}$ ions and finally dried at $40{ }^{\circ} \mathrm{C}$ overnight. In this way, the following alginate-zein (A-Z) bionanocomposite beads were prepared: A-Z@MCPA-LDH and A-Z@MCPA-LDH/Sep0.5:1_60C, incorporating the intercalation compound or the hybrid nanoarchitecture, respectively.

\section{Characterization}

Powder X-ray diffraction (XRD) data were collected on a Bruker D8 Advance diffractometer using a $\mathrm{Cu} \mathrm{K} \alpha$ source, with a $2 \theta$ scan step of $2^{\circ} \cdot \mathrm{min}^{-1}$ between 2 and $70^{\circ}$. The amount of the MCPA herbicide incorporated into the MCPA-LDH intercalation compounds and the MCPA-LDH/Sep hybrid nanoarchitectures was determined by $\mathrm{CHN}$ elemental chemical analysis using a LECO-CHNS-932 analyzer. Fourier transform infrared spectra (FTIR) were recorded from 4000 to $400 \mathrm{~cm}^{-1}$ with $2 \mathrm{~cm}^{-1}$ resolution in a Bruker IFS 66V-S spectrometer. Samples were prepared as pellets diluted in $\mathrm{KBr}$ or as pure samples pressed to form a tablet. ${ }^{29} \mathrm{Si}$ solid-state MAS spectroscopy at 79.49 MHz was carried out on a BRUKER AV-400-W spectrometer equipped with a $4 \mathrm{~mm}$ MAS NMR probe, with the samples rotating at a rate of approximately $10 \mathrm{kHz}$ and using a $\pi / 2$ pulse of recycle delay of $5.9 \mu \mathrm{s}$ and $5.0 \mathrm{~s}$. Chemical shifts are referenced to tetramethylsilane (TMS) at $\delta=0 \mathrm{ppm}$. Surface morphology of the samples was studied with the fieldemision scanning electronic microscope (FE-SEM) FEI-NOVA NanoSEM 230, and TEM images were performed on a JEOL 2100F STEM $200 \mathrm{kV}$ microscope.

\section{Release of MCPA in water}

The release of MCPA from the MCPA-LDH hybrid, MCPA$\mathrm{LDH} / \mathrm{Sep}$ nanoarchitectures and the A-Z bionanocomposite materials was performed in $100 \mathrm{~mL}$ deionized water at $\mathrm{pH} 5.5$, with the addition of the required quantity of material to provide $20 \mathrm{mg}$ of MCPA. The experiment was maintained at room tem- 
perature under slow magnetic stirring. At predetermined times, aliquots of $3 \mathrm{~mL}$ were analyzed and evaluated by UV spectrophotometry at $279 \mathrm{~nm}$ [51] to determine the concentration of the released herbicide. After the analysis, the collected solution was returned to the initial solution to keep the volume constant. All experiments were performed in triplicate.

\section{Supporting Information}

\section{Supporting Information File 1}

Additional experimental data.

[https://www.beilstein-journals.org/bjnano/content/ supplementary/2190-4286-10-163-S1.pdf]

\section{Acknowledgements}

This work was supported by the MINECO (Spain, project MAT2015-71117-R) and CNPq (Brazil, fellowship 204360/ 2014-5).

\section{ORCID ${ }^{\circledR}$ iDs}

Ediana Paula Rebitski - https://orcid.org/0000-0003-4401-9347 Margarita Darder - https://orcid.org/0000-0002-7032-0419 Pilar Aranda - https://orcid.org/0000-0003-2196-0476

\section{References}

1. Aono, M.; Bando, Y.; Ariga, K. Adv. Mater. (Weinheim, Ger.) 2012, 24 , 150-151. doi:10.1002/adma.201104614

2. Komiyama, M.; Yoshimoto, K.; Sisido, M.; Ariga, K. Bull. Chem. Soc. Jpn. 2017, 90, 967-1004. doi:10.1246/bcsj.20170156

3. Ariga, K., Ed. Manipulation of Nanoscale Materials: An Introduction to Nanoarchitectonics; Nanoscience \& Nanotechnology Series, Vol. 24; Royal Society of Chemistry: Cambridge, United Kingdom, 2012. doi:10.1039/9781849735124

4. Khan, A. H.; Ghosh, S.; Pradhan, B.; Dalui, A.; Shrestha, L. K.; Acharya, S.; Ariga, K. Bull. Chem. Soc. Jpn. 2017, 90, 627-648. doi:10.1246/bcsj.20170043

5. Ariga, K.; Mori, T.; Shrestha, L. K. Chem. Rec. 2018, 18, 676-695. doi:10.1002/tcr.201700070

6. Galarneau, A.; Barodawalla, A.; Pinnavaia, T. J. Nature 1995, 374, 529-531. doi:10.1038/374529a0

7. Gil, A.; Korili, S. A.; Trujillano, R.; Vicente, M. A. V., Eds. Pillared Clays and Related Catalysts; Springer: New York, NY, U.S.A., 2010. doi:10.1007/978-1-4419-6670-4

8. Aranda, P.; Belver, C.; Ruiz-Hitzky, E. Inorganic heterostructured materials based on clay minerals. In Materials and Clay Minerals; Drummy, L. F., Ed.; CMS Workshop Lectures Series, Vol. 18; Clay Mineral Society: Chantilly, VA, U.S.A., 2014; pp 21-40. doi:10.1346/cms-wls-18-2

9. Ruiz-Hitzky, E.; Aranda, P.; Belver, C. Nanoarchitectures Based on Clay Materials. In Manipulation of Nanoscale Materials: An Introductions to Nanoarchitectonics; Ariga, K., Ed.; Nanoscience \& Nanotechnology Series, Vol. 24; Royal Society of Chemistry: Cambridge, United Kingdom, 2012; pp 89-111. doi:10.1039/9781849735124-00087
10. Ruiz-Hitzky, E.; Aranda, P. J. Sol-Gel Sci. Technol. 2014, 70, 307-316. doi:10.1007/s10971-013-3237-9

11. Aranda, P.; Belver, C.; Ruiz-Hitzky, E. Nanoarchitectures by Sol-Gel from Silica and Silicate Building Blocks. In The Sol-Gel Handbook: Synthesis, Characterization and Applications; Levy, D.; Zayat, M., Eds.; Wiley-VCH Verlag GmbH: Weinheim, Germany, 2015; Vol. 1, pp 443-470. doi:10.1002/9783527670819.ch14

12. Aranda, P.; Darder, M.; Wicklein, B.; Rytwo, G.; Ruiz-Hitzky, E. Clay-Organic Interfaces for Design of Functional Hybrid Materials. In Hybrid Organic-Inorganic Interfaces: Toward Advanced Functional Materials; Delville, M. H.; Taubert, A., Eds.; Wiley-VCH Verlag GmbH: Weinheim, Germany, 2017; pp 1-84. doi:10.1002/9783527807130.ch1

13. Lvov, Y.; Guo, B.; Fakhrullin, R. F., Eds. Functional Polymer Composites with Nanoclays; Smart Materials Series, Vol. 22; Royal Society of Chemistry: Cambridge, United Kingdom, 2016. doi:10.1039/9781782626725

14. Aranda, P.; Ruiz-Hitzky, E. Chem. Rec. 2018, 18, 1125-1137. doi:10.1002/tcr.201700113

15. Vinokurov, V. A.; Stavitskaya, A. V.; Glotov, A. P.; Novikov, A. A.; Zolotukhina, A. V.; Kotelev, M. S.; Gushchin, P. A.; Ivanov, E. V.; Darrat, Y.; Lvov, Y. M. Chem. Rec. 2018, 18, 858-867. doi:10.1002/tcr.201700089

16. Brauner, K.; Preisinger, A. Tschermaks Mineral. Petrogr. Mitt. 1956, 6, 120-140. doi:10.1007/bf01128033

17. Santaren, J.; Sanz, J.; Ruiz-Hitzky, E. Clays Clay Miner. 1990, 38, 63-68. doi:10.1346/ccmn.1990.0380109

18. Aranda, P.; Ruiz-Hitzky, E. Nanoarchitectures based on sepiolite: assembly of nanoparticles. In Surface Modification of Clays and Nanocomposites; Beall, G.; Powell, C. E., Eds.; CMS Workshop Lectures Series, Vol. 20; Clay Minerals Society: Chantilly, VA, U.S.A., 2016; pp 87-100. doi:10.1346/cms-wls-20.7

19. Fernandes, F. M.; Ruiz-Hitzky, E. Carbon 2014, 72, 296-303. doi:10.1016/j.carbon.2014.02.009

20. Perez-Carvajal, J.; Aranda, P.; Ruiz-Hitzky, E. J. Solid State Chem. 2019, 270, 287-294. doi:10.1016/j.jssc.2018.11.018

21. Forano, C.; Hibino, T.; Leroux, F.; Taviot-Guého, C. Layered doublé hydroxides. In Handbook of Clay Science; Bergaya, F.; Theng, B. K. G.; Lagaly, G., Eds.; Elsevier: Oxford, United Kingdom, 2006; pp 1021-1095.

22. Forano, C.; Bruna, F.; Mousty, C.; Prevot, V. Chem. Rec. 2018, 18, 1150-1166. doi:10.1002/tcr.201700102

23. Wu, M. J.; Wu, J. Z.; Zhang, J.; Chen, H.; Zhou, J. Z.; Qian, G. R.; Xu, Z. P.; Du, Z.; Rao, Q. L. Catal. Sci. Technol. 2018, 8, 1207-1228. doi:10.1039/c7cy02314f

24. Zhao, M.; Zhao, Q.; Li, B.; Xue, H.; Pang, H.; Chen, C. Nanoscale 2017, 9, 15206-15225. doi:10.1039/c7nr04752e

25. Park, D.-H.; Hwang, S.-J.; Oh, J.-M.; Yang, J.-H.; Choy, J.-H. Prog. Polym. Sci. 2013, 38, 1442-1486. doi:10.1016/j.progpolymsci.2013.05.007

26. Leroux, F., Ed. Layered Double Hydroxide-based materials. Recent Pat. Nanotechnol. 2012, 6, 157-249.

27. Rives, V.; del Arco, M.; Martín, C. Appl. Clay Sci. 2014, 88-89, 239-269. doi:10.1016/j.clay.2013.12.002

28. Choi, G.; Eom, S.; Vinu, A.; Choy, J.-H. Chem. Rec. 2018, 18, 1033-1053. doi:10.1002/tcr.201700091

29. Nuruzzaman, M.; Rahman, M. M.; Liu, Y.; Naidu, R. J. Agric. Food Chem. 2016, 1447-1483. doi:10.1021/acs.jafc.5b05214

30. Gunjakar, J. L.; Kim, T. W.; Kim, H. N.; Kim, I. Y.; Hwang, S.-J. J. Am. Chem. Soc. 2011, 133, 14998-15007. doi:10.1021/ja203388r 
31. Gómez-Avilés, A.; Aranda, P.; Ruiz-Hitzky, E. Appl. Clay Sci. 2016, 130, 83-92. doi:10.1016/j.clay.2015.12.011

32. Djellali, M.; Aranda, P.; Ruiz-Hitzky, E. Appl. Clay Sci. 2019, 171, 65-73. doi:10.1016/j.clay.2019.02.004

33. Aranda, P.; Gómez Avilés, A.; Ruiz Hitzky, E. Materiales composites micro- y nano-estructurados basados en hidróxidos dobles laminares de tipo hidrotalcita y silicatos de la familia de las arcillas. Span. Patent ES2341637B1, May 23, 2011.

34. Tian, N.; Tian, X.; Liu, X.; Zhou, Z.; Yang, C.; Ma, L.; Tian, C.; Li, Y.; Wang, Y. Chem. Commun. 2016, 52, 11955-11958. doi:10.1039/c6cc05659h

35. Charradi, K.; Ahmed, Z.; Cid, R. E.; Aranda, P.; Ruiz-Hitzky, E.; Ocon, P.; Chtourou, R. Int. J. Hydrogen Energy 2019, 44, 10666-10676. doi:10.1016/j.ijhydene.2019.02.183

36. Alcântara, A. C. S.; Aranda, P.; Darder, M.; Ruiz-Hitzky, E. J. Mater. Chem. 2010, 20, 9495-9504. doi:10.1039/c0jm01211d

37. Inacio, J.; Taviot-Guého, C.; Forano, C.; Besse, J. P. Appl. Clay Sci. 2001, 18, 255-264. doi:10.1016/s0169-1317(01)00029-1

38. Cardoso, L. P.; Celis, R.; Cornejo, J.; Valim, J. B. J. Agric. Food Chem. 2006, 54, 5968-5975. doi:10.1021/jf061026y

39. Alromeed, A. A.; Scrano, L.; A. Bufo, S.; Undabeytia, T. Pest Manage. Sci. 2015, 71, 1303-1310. doi:10.1002/ps.3929

40. Pavlovic, I.; Barriga, C.; Hermosín, M. C.; Cornejo, J.; Ulibarri, M. A. Appl. Clay Sci. 2005, 30, 125-133. doi:10.1016/j.clay.2005.04.004

41. Miyata, S. Clays Clay Miner. 1975, 23, 369-375. doi:10.1346/ccmn.1975.0230508

42. Atçay, G.; Yurdakoç, K. Acta Hydrochim. Hydrobiol. 2000, 28 , 300-304. doi:10.1002/1521-401x(200012)28:6<300::aid-aheh300>3.3.co;2-c

43. Ahlrichs, J. L. Clays Clay Miner. 1975, 23, 119-124. doi:10.1346/ccmn.1975.0230207

44. Casal, B.; Merino, J.; Serratosa, J.-M.; Ruiz-Hitzky, E. Appl. Clay Sci. 2001, 18, 245-254. doi:10.1016/s0169-1317(01)00030-8

45. Alcântara, A. C. S.; Darder, M.; Aranda, P.; Tateyama, S.; Okajima, M. K.; Kaneko, T.; Ogawa, M.; Ruiz-Hitzky, E. J. Mater. Chem. A 2014, 2, 1391-1399. doi:10.1039/c3ta14145d

46. Akkari, M.; Aranda, P.; Ben Rhaiem, H.; Ben Haj Amara, A.; Ruiz-Hitzky, E. Appl. Clay Sci. 2016, 131, 131-139. doi:10.1016/j.clay.2015.12.013

47. Akkari, M.; Aranda, P.; Ben Haj Amara, A.; Ruiz-Hitzky, E. Beilstein J. Nanotechnol. 2016, 7, 1971-1982. doi:10.3762/bjnano.7.188

48. de la Caillerie, J.-B. d.; Fripiat, J. J. Catal. Today 1992, 14, 125-140. doi:10.1016/0920-5861(92)80017-h

49. López-Capdevila, S.; Darder, M.; Aranda, P.; Ruiz-Hitzky, E. In Actas de la Jornada Científica de la Sociedad Española de Arcillas; Belver, C.; Cuevas, J.; Luque, J., Eds.; Socieda Española de Arcillas: Madrid, Spain, 2011; pp 23-24.

50. Bruna, F.; Celis, R.; Pavlovic, I.; Barriga, C.; Cornejo, J.; Ulibarri, M. A. J. Hazard. Mater. 2009, 168, 1476-1481. doi:10.1016/j.jhazmat.2009.03.038

51. Cardoso, L. P.; Valim, J. B. J. Phys. Chem. Solids 2006, 67, 987-993. doi:10.1016/j.jpcs.2006.01.015

\section{License and Terms}

This is an Open Access article under the terms of the Creative Commons Attribution License (http://creativecommons.org/licenses/by/4.0). Please note that the reuse, redistribution and reproduction in particular requires that the authors and source are credited.

The license is subject to the Beilstein Journal of Nanotechnology terms and conditions: (https://www.beilstein-journals.org/bjnano)

The definitive version of this article is the electronic one which can be found at: doi:10.3762/bjnano. 10.163 